\title{
Concepção de educação social em Vigotski: apontamentos para o processo de escolarização de crianças com deficiência
}

\author{
Débora Dainez* \\ Ana Paula de Freitas**
}

\begin{abstract}
Resumo
Por meio de um trabalho investigativo teórico-conceitual, busca-se explanar o constructo educação social abordado por Vigotski, sobretudo, em seus estudos sobre a deficiência. O objetivo é evidenciar os princípios e pressupostos, assim como explorar ideias elaboradas pelo autor em relação aos processos educacionais e sua função na formação integral e desenvolvimento cultural da personalidade. Argumenta-se a favor de um projeto educacional transformador, que torne acessível aos sujeitos com deficiência formas conscientes de desenvolvimento da atividade coletivamente organizada/planejada, sustentando modos de participação efetiva nas múltiplas dimensões da vida associada, perspectivada, colaborativa.

Palavras-chave: Educação social; Educação inclusiva; Educação especial; Desenvolvimento humano; Perspectiva histórico-cultural.
\end{abstract}

\section{Social education approach according to Vygotsky: notes for the schooling process of children with disabilities}

\begin{abstract}
Through theoretical-conceptual research, we seek to explain the construct of "social education," addressed by Vygotsky mainly in his studies on disability. The objective is to highlight the principles and assumptions, as well as to explore the ideas developed by the author as to the educational processes and their function in the integral formation and the cultural development of the personality. We discuss and advocate a transformational educational project that allows people with disabilities to access conscious forms of development of collectively organized and planned activities, sustaining modes of active participation in the multiple dimensions of associated, prospective, and collaborative life.

Keywords: Social education; Inclusive education; Special education; Human development; Cultural-historical approach.
\end{abstract}

\section{Introdução}

As obras de Lev S. Vigotski, produzidas há praticamente um século, pulsam intensamente na nossa contemporaneidade. Os estudos que elaborou são amplamente conhecidos e além de embasarem pesquisas situadas em diferentes áreas do conhecimento, são tomados como lócus de análise, problematização e discussão teórico-metodológica. Seus trabalhos seminais são colocados em movimento no processo histórico de produção do conhecimento, fomentando um território fértil de pesquisas. Temos voltado a esse pensador não como uma personalidade notável do passado, mas como um autor cujas ideias e pressupostos estão vivos em nosso meio social, científico.

A validade atual de seus escritos, a nosso ver, não se deve ao fato de que Vigotski foi "além de seu tempo", já que a sua criação revolucionária em psicologia coincidiu plenamente com o momento histórico de produção, com o clímax revolucionário

*Endereço eletrônico: ddainez@ yahoo.com.br

***Endereço eletrônico: freitas.apde @ gmail.com inscrito naquela prática social (TULESKI, 2008; SHUARE, 2017). Consideramos que os seus trabalhos ressoam hoje com erudição crítica pelo valor heurístico de suas teses, pelo rigor em relação aos fundamentos teórico-metodológicos e, especialmente, pelo intenso engajamento com as demandas que o contexto pós-revolução - que se desenrolou na Rússia no início do século XX -, colocava na direção da reconstrução da sociedade tendo em vista a formação do homem novo.

Concordamos com Shuare (2017) quando pontua que Vigotski não formula a sua teoria a partir de fatos isolados obtidos experimentalmente, tampouco a partir de uma reflexão escolástica abstrata; e sim, elabora princípios epistemológicos ancorando-os na concretude da vida.

Nessa mesma linha de reflexão, Stetsenko $(2016,2017)$ argumenta que o teor do pensamento vigotskiano se difere de outros pensadores no campo da psicologia, visto que, juntamente com a atividade acadêmica, Vigotski se fez um ativista civil, 
envolvido diretamente com empreendimentos práticos e políticos de reorganização do sistema nacional de educação.

Conforme relatos das pesquisadoras russas Inna Koperanova e Tatiana Akhutina ${ }^{1}$, quando, no ano de 1924, o Ministério da Educação da URSS solicita aos pesquisadores o preenchimento de um questionário relativo à área na qual o Estado poderia utilizá-los para colaborar com o trabalho, Vigotski responde que poderia contribuir na área da educação e desenvolvimento de crianças com deficiência, chamada defectologia. Desde então, a questão da deficiência permaneceu como um dos principais núcleos de seus interesses científicos. Fomentou o seu trabalho investigativo acerca da íntima relação sociedade, educação e desenvolvimento humano.

Esse fato demonstra o compromisso do autor em contribuir com a criação de condições de desenvolvimento de grupos submetidos a processos de exclusão pela situação de vulnerabilidade e desigualdade social. De acordo com Stetsenko (2016, 2017), o projeto teórico-metodológico-prático, apresentado por Vigotski, se tonifica na contemporaneidade pelo ethos sociopolítico da igualdade e da justiça social que traz em seu bojo explicativo/propositivo.

Nas palavras de Shuare (2017, p.72),

Em nenhuma outra área, como a defectologia, na clínica das afecções cerebrais e na psicopatologia talvez se descubra o caráter profundamente humanista da concepção de Vigotski. Aí, na enfermidade, no defeito, na insuficiência e na incapacidade desenham-se plenamente as perspectivas de sua teoria, cujo núcleo de sentido é o profundo otimismo nas possibilidades do homem como sujeito da atividade, criador de sua própria história, artífice do seu desenvolvimento.

Destacamos, com isso, a atualidade e a importância científica e social apresentada nos trabalhos elaborados por Vigotski. As bases que constrói tornam-se relevantes para o desenvolvimento de práticas sociais, especialmente a educação de crianças com deficiência.

A concepção de deficiência e suas implicações educacionais se colocavam como uma das principais preocupações de Vigotski $(1997)^{2}$. O autor analisou criticamente as abordagens defectológicas e os princípios educativos e organizativos da escola especial da sua época. Nessas discussões chamou a atenção para a importância da educação especial ser focalizada pelo prisma da educação social, pautada na atividade laboral e na formação da personalidade.

É interessante notar que, particularmente, são nos textos da defectologia que o autor trabalha $\mathrm{e}$ expande a concepção de educação social em articulação com o problema da formação integral e desenvolvimento cultural da personalidade.

Essa ideia se apresenta para nós como fonte de provocações e potencial de elaborações prospectivas no que diz respeito aos processos educacionais envolvendo pessoas com deficiência. Como Vigotski trabalha a concepção de educação social? Quais são os pressupostos e os argumentos elaborados nessa discussão? E quais são os possíveis apontamentos para o processo de escolarização de crianças com deficiência na contemporaneidade?

Dessa forma, tomamos o constructo educação social como objeto de estudo e problematização. Temos como objetivo explaná-lo de modo a evidenciar os princípios e compreender os argumentos elaborados por Vigotski em relação aos processos educacionais e sua função na formação integral e desenvolvimento cultural da personalidade. $\mathrm{O}$ propósito é avançarmos nos fundamentos teóricos e discutirmos suas implicações na realidade social.

Com inspiração no método dialético trabalhado por Vigotski (1995, 2000), em que se busca estudar o objeto em movimento no seu desenvolvimento histórico, assumimos uma metodologia transformativa orientada por problemáticas sociais.

A partir de uma leitura detalhada dos textos de Vigotski, principalmente, aqueles reunidos na obra "Fundamentos de defectologia", abordamos a educação social considerando o entrelaçamento das ideias produzidas pelo autor acerca dessa discussão, bem como o conteúdo das mesmas. Trata-se, portanto, de um trabalho investigativo teóricoconceitual (DEMO, 2000), cuja análise apresenta um caráter exploratório, compreensivo e explicativo, assentado na derivação de uma lógica interna que apreendemos no estudo minucioso dos escritos do autor.

Em um primeiro eixo de discussão explanamos a articulação do constructo educação social com a ideia de atividade laboral. Exploramos, em seguida, a função da educação social na formação integral e desenvolvimento cultural da personalidade de crianças com deficiência. Após, tecemos algumas considerações sobre as diferenças nos modos de qualificar e de conceber a educação social em Vigotski e a educação inclusiva na contemporaneidade. 


\section{Educação Social e Atividade Laboral}

Já nos primeiros textos da defectologia, escritos e publicados nos anos de 1924, 1925 e 1927, vemos o empenho de Vigotski em discutir criteriosamente o problema da educação de crianças com deficiência naquela conjuntura revolucionária. Esse empreendimento se respalda em uma concepção de homem e seu desenvolvimento ancorada nos fundamentos do materialismo histórico-dialético. Nessa perspectiva, assume-se que a desigualdade entre os homens não emana das incapacidades biológicas, mas da desigualdade econômica, da divisão das classes sociais, que demarca a disparidade dos meios de apropriação dos bens culturais acumulados no processo histórico de produção. As condições de possibilidades de desenvolvimento humano ultrapassam, portanto, os limites impostos pela natureza/desigualdade inata.

Ao discorrer sobre o princípio da sociogênese, Vigotski (1995, p.89) afirma que "es la sociedad y no la naturaliza la que debe figurar em primer lugar como el fator determinante de la conducta del hombre ${ }^{3 "}$. Explicita-se nessa tese o pressuposto da constituição social do psiquismo e a hipótese de que o desenvolvimento cultural da criança está intrinsicamente ligado à educação. Quer dizer, os processos sociais participam do desenvolvimento das funções psíquicas, cuja emergência se manifesta nas formas de interação, de colaboração, de mediação, de atividade, de ensinoaprendizagem.

Partindo dessas premissas, o autor teceu contundentes críticas referentes àquela forma de organização da escola especial por investir em programas educacionais com métodos de ensino simplificados e objetivos reduzidos, que suscitavam práticas corretivas centradas na insuficiência física, motora, sensorial, comportamental, intelectual. Contestou as orientações médico-pedagógicas que buscavam caracterizar as crianças com deficiência levando em consideração as diferenças quantitativas do intelecto, da motricidade - baixo nível de inteligência e de memória, menor força muscular, etc.. Debateu visões segundo as quais, as crianças com deficiência, principalmente as com deficiência intelectual, não poderiam ser criadoras e construtoras de uma nova vida, tendo relações reduzidas com o trabalho; suposição essa que conduziria a uma educação pautada em treinos e rotinas, em tarefas manuais repetitivas.

Com efeito, o autor ressalta que historicamente as bases da educação especial ancoravam-se no assistencialismo/caridade social, nas distorções produzidas pelo significado social do déficit, tendo como orientador o princípio da invalidez/improdutividade social.

Considerando os aspectos qualitativos das funções psíquicas, quer dizer, os modos singulares de constituição, os processos dinâmicos e prospectivos de desenvolvimento, Vigotski (1997) assegurou ser papel da escola gerar modos de trabalho que respondam às peculiaridades e às possibilidades de desenvolvimento cultural dos alunos com deficiência. Com isso, a educação especial deveria ser repensada no âmbito da educação geral, em termos de uma educação social pautada na atividade laboral, com vistas à ampliação dos processos de humanização.

Nessa discussão, o trabalho é tomado como domínio em torno do qual a escola deve se organizar. Uma vez que a vida social do homem e seu estudo da natureza estão ligados ao trabalho, a educação social laboral se configura como instância de participação ativa e prospectiva da criança nas relações e produções humanas.

Em diálogo com educadores soviéticos, sobretudo com N.K. Krúpskaya, Vigotski (1997, 2004) defendeu uma educação social orientada à vida objetiva, que tratasse do lugar da escola na sociedade trabalhadora (BARROCO, 2007). Para tanto, explora essa concepção com base na categoria de trabalho do materialismo histórico-dialético. Conceito esse que ocupa uma posição nuclear nas obras de Marx e Engels (ENGELS, 1999; MARX; ENGELS, 2007; MARX, 2011).

Ao enfatizar a dimensão vital do trabalho, de manutenção da vida humana, concebendo-o como atividade que confere as características singulares do homem, Engels (1999, p.4) chegou a afirmar que "o trabalho criou o próprio homem". O trabalho é tido como uma atividade especificamente humana, por meio da qual o homem desprendeu-se da natureza e passou a ter domínio da própria conduta. Diferentemente das demais espécies animais, o homem se diferencia da natureza e a transforma na atividade de trabalho, ao mesmo tempo, se constitui nesse processo, criando novas forças e funções psíquicas.

Como fora analisado por Marx (2011), o processo de trabalho consiste em uma atividade planejada, orientada a um fim, para a criação de produto útil à vida humana. Requer matéria, que será transformada em produto, e implica criação e uso de instrumentos, os quais cumprem a função de orientar a ação do sujeito sobre o objeto. No processo de 
produção o homem subordina a sua vontade a uma atividade orientada por um objetivo coletivamente delineado. Antecipa, projeta o produto e seu valor/função social; produto esse que, além de ser resultado, cria novas necessidades sociais, abre possibilidades para o avanço no processo de trabalho e amplia o potencial humano. A atividade laboral "exige a vontade orientada a um fim, que se manifesta como atenção do trabalhador durante a realização de sua tarefa" (MARX, 2011, p. 327-328, grifo nosso).

Essa atividade humana, segundo Vigotski (1995), Leontiev (1978) e Luria (1979), viabilizou a produção e o uso de instrumentos e signos, condicionou a emergência da linguagem, que transformou a relação imediata do homem com a natureza em uma relação intencional, planejada, perspectivada e prospectiva. Essas novas formações elevaram as condutas físicas e sensoriais aos complexos processos psíquicos, provocaram mudanças substanciais de maneira a possibilitar a constituição mediada do psiquismo e a elaboração histórica da consciência.

Em suas discussões sobre a educação de crianças com deficiência, Vigotski (1997) evidencia o problema da vontade. Parte do princípio de que o desenvolvimento volitivo é coletivamente orientado, ou seja, a regulação dos processos psíquicos é geneticamente social. As formas de conduta são inter/hetero/autorreguladas e assumem papel constitutivo da personalidade. Quer dizer, as regras da coletividade, possíveis no processo histórico do desenvolvimento da humanidade, se manifestam na configuração da personalidade como uma forma completamente nova, tornam-se função psíquica própria.

Os processos volitivos se constituem então na complexa dependência genética entre a forma coletiva de colaboração e o modo singular de apropriação. As capacidades de dominar comportamentos impulsivos, de guiar a própria conduta, de coordenar as ações com as ações do outro, se manifestam nas formas coletivas de atividade.

Dessa forma, compreende-se que a impossibilidade de desenvolvimento dos processos volitivos não é intrínseca à deficiência, mas ligada aos vínculos sociais, às formas de colaboração, às possibilidades concretas que o sujeito encontra de envolvimento na atividade coletiva. Por esse ângulo, ao considerarmos o trabalho enquanto atividade de autorrealização da existência humana, é possível conjecturar como o sentido social e o valor de uso impresso na atividade, no produto projetado, afeta a dimensão volitiva do sujeito que a realiza.

Vigotski (1997, p.65) pergunta: "Qué resultados puede haber cuando el alumno es sólo un ejecutor, por quién otro realiza el trabajo de organización y que por no estar habituado a la colaboración en las tareas resulta un inválido cuando sale de la escuela?"4. Essa indagação do autor nos remete às tarefas escolares meramente executivas, automatizadas, que excluem os elementos coletivos de planejamento e organização, impossibilitam o envolvimento e a disposição do sujeito. Perde-se o sentido social da atividade, tornando trabalho forçado, imposto. $\mathrm{O}$ sujeito não se reconhece no produto da tarefa desempenhada, fica sem condições de definir objetivos, de se autoconduzir e dominar o processo de desenvolvimento da atividade. Temos, assim, uma prática educativa que prepara para especialidades alienantes e não forma pela/para a atividade laboral transformadora.

$\mathrm{O}$ argumento que se sobressai nessa discussão é que a perda do aspecto coletivamente organizado/planejado do trabalho, a separação entre a dimensão intelectual e a dimensão técnica no processo educacional corrompe o potencial de humanização e o desenvolvimento da personalidade a níveis mais complexos.

A forma alienante do trabalho na sociedade capitalista foi abordada pelo autor sobretudo no texto "A transformação socialista do homem", de 1930. Partindo do pressuposto de que o desenvolvimento humano é determinado pelos modos e relações de produção, Vigotski (2004) analisou que cada novo patamar das forças sociais produtivas conduziu a degradação mais profunda do humano e de seu potencial de desenvolvimento omnilateral. A divisão do trabalho, pautada em operações fracionadas/parceladas, sustenta a divisão da sociedade em classes que gera a secção do homem, efetuando um desenvolvimento unilateral.

De acordo com as análises do autor, as fontes para a transformação da personalidade humana estariam ligadas à transformação da ordem social, das relações sociais, que orientam mudanças nas ideias, nos padrões de comportamento, nos valores, nas exigências, nos pequenos gestos... A educação social laboral, que unifica trabalho e ensino, participa desse processo ao ancorar a inserção das crianças nas formas de colaboração coletiva, as quais são percursoras do desenvolvimento de uma série de funções psíquicas culturalmente mediadas. As crianças com deficiência são convocadas a participar ativamente das atividades coletivas, a valer-se das 
formas elaboradas de colaboração, tendo condições de desenvolvimento da linguagem, do pensamento, da consciência, da personalidade.

Essa perspectiva nos faz ter em vista as possibilidades de desenvolvimento da atividade psíquica do sujeito no âmago do desenvolvimento do trabalho coletivo, organizado, com objetivo, sentido e valoração social.

Nessa direção desponta-se o papel da escola em criar condições de apropriação dos princípios científicos gerais dos processos sociais de produção humana, das formas de domínio sobre as forças da natureza (MARX; ENGELS, 2011). O conteúdo do ensino na perspectiva da educação social laboral vale-se das interrelações entre o homem e a natureza, o indivíduo e a sociedade, os nexos do presente, do passado, com orientação para o futuro da vida humana.

Trata-se de desenvolver nas crianças com deficiência a concepção científica de mundo e alimentar um modo consciente para a vida futura, efetivando meios de cooperação, compreensão da interdependência dos fenômenos e de criação do novo.

É nesse sentido transformador que o constructo de educação social com ênfase na atividade laboral é trabalhada pelo autor nos textos sobre o desenvolvimento e a educação de crianças com deficiência. O seu esforço de elaboração reflete a incorporação da diretriz do trabalho como princípio educativo, potencializador do processo de humanização. Ressalta-se a proposição de que é por meio da organização ativa da vida na escola que os alunos com deficiência poderão fazer parte da vida social comum.

Em seus termos,

Aunque los niños mentalmente retrasados estudien más prolongadamente, (...) aunque, por último, se les enseñe de otro modo, aplicando métodos y procedimentos especiales, adaptados a las características específicas de su estado, deben estudiar lo mismo que todos los demás niños, recibir la misma preparación para la vida futura, para que después participen en ella, en certa medida, a la par com los demás ${ }^{5}$ (VIGOTSKI, 1997, p.149).

Por meio de uma educação social laboral significativa/participativa/criadora é possível converter o limite em potencial, produzindo condições de envolvimento dessas crianças em atividades transformadoras na trama da vida comum, ampliando os nexos sociais da personalidade.

Realça-se, portanto, a ideia de que a educação social laboral envolva a educação de crianças com deficiência tendo como propósito o desenvolvimento omnilateral, ou seja, uma educação com foco na formação integral da personalidade.

\section{Educação Social e sua Função na Formação Integral e Desenvolvimento Cultural da Personalidade}

Estabelecer as regularidades comuns do desenvolvimento da criança e estudar suas manifestações específicas demarca a atividade investigativa de Vigotski (1995,1997). Explicita-se no modo de teorizar do autor a busca constante pelas leis gerais de desenvolvimento e ao mesmo tempo a preocupação com as variantes qualitativas do processo. Isso demonstra o modo como ele compreende o desenvolvimento na sua dinamicidade e heterogeneidade (DAINEZ, 2017).

Ao elaborar a lei da transformação das formas coletivas de colaboração em formas de atividade psíquica da personalidade, Vigotski (1997) focaliza a relação da criança com deficiência com o meio social e considera que o déficit orgânico provoca uma orientação social peculiar. Isso porque o déficit orgânico desregula formas de conduta pressupostas e estabilizadas em dada ordem social, afeta a situação social do sujeito relacionada a cada período de desenvolvimento. Dizendo de outro modo, a condição orgânica não coincide com a condição social, com o que é esperado, desejado, convencionalizado em determinada forma de organização da sociedade.

Essa alteração correlativa é notável ainda na ambiência familiar, primeira esfera de inserção social do sujeito, em que a criança com deficiência é recebida e frequentemente significada como especial, inabitual. Ocupa uma posição na qual se inscreve, por um lado, sentidos de piedade, de cuidado e proteção redobrada; e por outro, abandono, rejeição, discriminação. Essa forma historicamente produzida de significar a condição do déficit marca a vivência da criança, define a sua inserção e participação social, delineia os processos educacionais e formativos da personalidade.

Nesse caso, os processos interacionais, os vínculos com as pessoas, a participação nas atividades sociais, as formas de colaboração, as funções de existência, se reorganizam sob um novo ângulo - da falta/ausência de funções, do desvio da norma. 
Portanto, não é o déficit em si que afeta diretamente as funções psíquicas, mas o déficit em determinada realidade sociocultural; o modo como é significado e compreendido socialmente torna-se condição de possibilidades ou impedimentos de desenvolvimento cultural da personalidade. É esse fenômeno que Vigotski (1997) nomeia como complicações secundárias, as quais são produzidas no âmbito das relações sociais, devido à intensificação dos obstáculos encontrados pela criança no meio em que se insere, e que se tornam constitutivas da personalidade.

Adensando a discussão sobre as consequências sociais do déficit orgânico na constituição da personalidade da criança com deficiência, Vigotski (1997) formula a ideia de que os órgãos físicos, no processo de humanização, tornam-se "órganos sociales" (p.74), impregnados de signos e sentidos, produzidos nas atividades sociais, que redimensionam a ordem da sensibilidade, cunham a dimensão simbólica.

Com isso, Vigotski $(1995,1997)$ busca explicar que o problema da inserção da criança com deficiência nas práticas sociais não se deve ao aparato psicofisiológico, mas ao domínio das funções psíquicas mediadas, produzidas no desenvolvimento histórico-cultural da humanidade. O que quer dizer que a especificidade que marca a formação da personalidade da criança com deficiência, não é apenas delimitada organicamente, mas tem em sua base um núcleo social; se configura como resultado da atividade subjetiva condicionada por condições objetivas.

Nas palavras do autor,

Así como el curso de un torrente está delimitado por las márgenes y el cauce, la línea psicológica directriz, el objetivo de la vida del hombre en desarrollo y crecimiento, están delimitados por la necesidad objetiva del cauce social y las márgenes sociales de la personalidad ${ }^{7}$. (VIGOTSKI, 1997, p.45).

Destaca-se nessa discussão a ideia de que o desenvolvimento cultural suplanta o desenvolvimento orgânico, formando um sistema funcional complexo qualitativamente novo. Isso nos dá a compreender que a personalidade se configura como uma unidade dialética das duas linhas de desenvolvimento que se entretecem na história de relações e produções humanas.

A partir desse pressuposto da formação social e interfuncional da personalidade, entende-se que a ausência de um órgão sensorial não acarreta naturalmente uma maior receptividade de outros órgãos sensoriais. Assim como o intelecto não é visto como uma estrutura homogênea, monolítica; mas como uma unidade complexa em que pese a diversidade de relações entre as funções. $O$ déficit intelectual, por exemplo, não se limita a perda isolada de uma função, e sim leva a uma reorganização integral de toda a personalidade, colocando em perspectiva novas "vías colaterales de desarrolllo cultural $^{8 "} \quad$ (VIGOTSKI, 1995, p.43). A interdependência relativa das funções cognitiva, afetiva, motriz, verbal se apresenta como uma condição plástica, repleta de novas conexões e modificações funcionais.

Nessa linha de pensamento, Vigotski (1997) considera que uma educação precária altera reais possibilidades de desenvolvimento das funções psíquicas, sobretudo quando pensamos na educação de crianças com deficiência. Toma, assim, a deficiência como um problema de educação social e destaca o conceito de compensação social como metodologia da educação social. Isso quer dizer que a produção dos modos de significação, de participação se desenha na coletividade. E que, a condição de deficiência demanda formas ainda mais próximas, guiadas e contínuas de mediação, recursos auxiliares para potencializar a participação da criança na atividade coletiva e colaborativa.

Explicita-se, então, no trabalho argumentativo do autor a tese da natureza social da deficiência e a função da educação de criar sistemas culturais auxiliares que sustentem o desenvolvimento cultural da personalidade.

Por meio do constructo educação social, Vigotski (1997) se posiciona, portanto, em defesa de uma educação que desloque o foco do déficit orgânico para a formação integral e desenvolvimento cultural da personalidade da criança; que deixe de ter como objetivo a correção sensorial e a adaptação ao meio, e passe a se orientar para a (trans)formação das funções psíquicas mediadas. Segundo ele, "no debemos olvidar que es preciso educar no a um ciego, sino ante todo a um niño" (VIGOTSKI, 1997, p.81).

O que se apresenta para nós é que a função de uma educação social seria a de criar vias de desenvolvimento de novas e complexas formações psíquicas (linguagem escrita, raciocino lógicomatemático, pensamento conceitual e metafórico, sentimento ético e estético...), viabilizando a inserção ativa da pessoa com deficiência na dinâmica da vida, ampliando a sua participação nas atividades sociais e laborais, elevando, com isso, os processos culturais constitutivos da personalidade. 
É possível assegurar, dessa forma, as mesmas leis de desenvolvimento e os mesmos princípios educativos para todas as crianças. O conteúdo qualitativo do ensino-aprendizagem segue sendo equivalente, a diferença está nos diversos mediadores de desenvolvimento cultural que podem ser criados e acionados na relação com o outro, no trabalho com o conhecimento. Em outros termos, considerando que o desenvolvimento das funções psíquicas pode ocorrer por canais distintos, apontamos para a importância das relações de ensino pautarem-se na heterogeneidade dos modos e meios de desenvolvimento cultural da personalidade.

Visto que "um indivíduo só existe como um ser social - como um membro de algum grupo social, em cujo contexto ele segue o percurso do desenvolvimento histórico...". (VIGOTSKI, 2004, $\mathrm{s} / \mathrm{p})$; contraditoriamente, se o modo de organização da vida social impõe obstáculos para a efetiva inserção e participação da criança com deficiência nas atividades e práticas, é na própria dinâmica social, por meio da educação, que é possível criar artefatos, instrumentos técnicos-semióticos que se tornem mediadores e extensores culturais das funções psíquicas. A função social, desempenhada na atividade coletivamente organizada, incide e redimensiona a dimensão orgânica ao se transformar em função psíquica mediada.

\section{Educação social e Educação inclusiva: modos de qualificar, modos de conceber}

Vimos chamando a atenção neste texto para a argumentação de Vigotski (1997) em prol de uma educação social para crianças com deficiência, isto é, uma educação atenta ao trabalho como núcleo humanizador, que as insira e as torne partícipes na/da vida em sociedade; uma educação escolar transformadora, que desloque o eixo orgânico da deficiência para o eixo das possibilidades sociais de desenvolvimento cultural da personalidade.

O fato de Vigotski (1997) defender que a educação de crianças com deficiência ocorra no âmbito da educação geral, muitas vezes soa nos dias de hoje como "ideias inclusivas". Além do paradigma da educação inclusiva ter sido difundido em outro contexto histórico, seus fundamentos se distanciam daqueles assumidos por Vigotski no constructo educação social.

A concepção de educação social se apresenta em tempos de educação inclusiva, com tons desafiadores e contornos inspiradores. Quando compreendemos que o meio social e sua estrutura é fator fundante de todo o sistema educativo, ampliamse os dilemas, acirram-se as tensões mediante uma sociedade organizada em classes e orientada por valores de mercado.

Sabemos que, desde a década de 1990 , e mais enfaticamente no início deste século, com indefinições e imprecisões, tem ocorrido mudanças conceituais e organizacionais do ensino para alunos com deficiência em nosso país. De uma educação especial constituída como uma rede paralela da educação comum (JANNUZZI, 1985, 2006), vamos tendo o delineamento de uma política de educação inclusiva que tem como meta a inserção compulsória de crianças com deficiência, transtornos globais do desenvolvimento, altas habilidades e superdotação no processo de escolarização.

Conforme apontado por Kuhnen (2017), a concepção de deficiência que rege a nossa legislação atual baseia-se ainda em uma visão tecnicista e na dicotomia normal e patológico. A autora ressalta que, com a perspectiva da educação inclusiva, não houve mudanças significativas na concepção de deficiência, apenas matizes de uma visão pós-moderna que redefine o normal e o patológico em termos de diferença e diversidade. Tais políticas se transformam em práticas, permeiam os processos educacionais. Trabalhos investigativos (PLETSCH, 2010; CARVALHO, 2013; DAINEZ, 2014; FREITAS; MONTEIRO; CAMARGO, 2015) apontam para o pressuposto da incapacidade/improdutividade permeando as relações de ensino e produzindo condições impeditivas de desenvolvimento cultural de alunos com deficiência.

Carvalho e Martins (2012) argumentam que o modelo de inclusão social não se mantém em uma sociedade de natureza capitalista uma vez que a concepção de desenvolvimento humano que a orienta é individual, competitiva e meritocrática. Sendo a exclusão parte do modelo capitalista de produção, Padilha e Oliveira (2013) salientam a lógica paradoxal que há em se propagar um discurso de inclusão social, quando apenas uma parcela mínima da população tem garantido o acesso aos bens materiais e simbólicos produzidos coletivamente, inclusive o direito à educação escolar de qualidade.

Pautada no lema 'escola para todos', subjaz a ideia de que a inclusão possibilita que os alunos que estavam apartados da vida escolar, passam a ter acesso à escola e ao conhecimento sistematizado. Todavia, paradoxalmente, o objetivo educacional volta-se para um ensino massificado e padronizado, que visa a conformação de subjetividades passivas. 
De acordo com Freitas (2010, p. 93) a forma escola hoje encontra-se "...isolada da vida, da prática social, do trabalho como atividade humana central para a existência, enfim, vê-se imersa na artificialidade de uma sala de aula sem significado para seus estudantes".

A implementação da política de educação especial na perspectiva da educação inclusiva segue em consonância com essa forma de organização escolar. Isso se manifesta sobretudo na implantação de um modelo padrão de atendimento educacional especializado direcionado à heterogeneidade de condições específicas dos alunos vinculados à educação especial (KASSAR, 2011; GARCIA, 2016). Dizendo de outro modo, segundo Garcia (2016), a educação especial na perspectiva inclusiva é redefinida em termos de atendimento educacional especializado na sala de recursos multifuncionais com tônica nos elementos de acessibilidade, pautada na racionalidade de redução de custos do atendimento, o que tende à tecnicização do trabalho pedagógico. Ainda, esse modelo inclusivo, considera a participação das instituições assistenciais na oferta desse atendimento; aspecto esse problematizado cuidadosamente por Siems-Marcondes e Caiado (2013).

Considerando essa realidade social e as tensões que perpassam o processo de escolarização de alunos com deficiência no âmbito das políticas de educação inclusiva, muitas indagações podem ser então levantadas: Qual é o objetivo educacional e a orientação do ensino envolvendo o público-alvo da educação especial? Qual é o vetor de desenvolvimento que incide na nossa realidade educacional? Como ensinar, por quais vias e tendo em vista que concepção de homem, de educação e de sociedade?

Compartilhamos uma situação extraída de nosso banco de dados, referente a uma pesquisa que focalizava práticas educacionais para alunos com deficiência no âmbito da educação comum. Na ocasião, a pesquisadora responsável acompanhava uma aluna com deficiência intelectual, na Educação Infantil. Semanalmente, realizava observações da aluna em diferentes situações escolares - atividades pedagógicas, horário de parque e alimentação registradas em videogravação.

A pesquisadora chegou à escola um pouco após o horário habitual, a professora lamenta seu atraso, alegando que a aluna, que estava em uma mesa com a monitora, já havia realizado sua atividade pedagógica. Então, a professora orienta a monitora a realizar novamente a tarefa - que consistia em colar bolinhas de papel crepom sobre o número quatro que estava grafado em uma folha de papel sulfite. A monitora escreve o número quatro em uma folha de papel sulfite e começa a auxiliar a aluna, que repete a tarefa - rasgar papel crepom, amassar as bolinhas e colá-las sob o número. Os demais alunos estavam aprendendo a quantidade quatro e faziam, com a professora, outras atividades para esse fim.

O que significa a aluna com deficiência fazer uma atividade diferente? Adaptada? E repetir o já feito? Qual é o sentido e o valor de uso da atividade? Enquanto a aluna com deficiência repete uma tarefa específica com a monitora, os demais alunos da turma realizam atividades conjuntas e diversas com a intermediação da professora. A criança com deficiência não é convocada a participar da elaboração e realização da atividade coletiva, apenas executa uma tarefa específica que não apresenta sentido, podendo ser repetida, inclusive, para demonstrar certas habilidades manuais à pesquisadora.

As condições escolares e o significado atribuído ao déficit nessa conjuntura socioeconômica impedem a realização de um trabalho educacional com objetivo comum, sentido e valor cultural. Isso é um fator limitante quando entendemos que as funções psíquicas emergem na relação com o desenvolvimento da atividade coletiva da criança.

Temos constatado alunos público-alvo da educação especial acompanhados por monitores, estagiários, que muitas vezes assumem uma função pedagógica, sem orientação e (in)formação para tanto, realizando tarefas mecânicas e desvinculadas de um trabalho intelectual (FREITAS; DAINEZ, 2018).

De acordo com Garcia (2016), mesmo buscando combater a educação segregada, a formulação da educação inclusiva na educação especial não se configura como prática transformadora. "Os mecanismos para minimizar a 'exclusão' da escola não superam os elementos que geram a desigualdade educacional relacionados a ensinar e aprender que, por sua vez, estão vinculados à dinâmica social vigente" (GARCIA, 2016, p.18).

A perspectiva inclusiva, embora contribua com a democratização do acesso ao sistema público de ensino, mediante seu arcabouço ideológico, circunscreve exigências mínimas de relação com o conhecimento e desloca a atividade laboral na sua complexidade.

Se por um lado, as condições concretas oferecidas no âmbito escolar não são as ideais, por outro lado, é por meio da educação, como prática 
social transformadora (STETSENKO, 2016, 2017), que vislumbramos condições de desenvolvimento humano.

Nesse sentido, a concepção de educação social trabalhada por Vigotski (1997, 2004) configura-se como uma diretriz ainda inovadora, que se apresenta como horizonte a ser projetado e atingido socialmente na educação de nossas crianças (com deficiência).

La ideia central consiste en que la educación se considera como parte de la vida social y como participación organizada de los niños en esa vida. La educación y la enseñanza en la sociedade, a través de la sociedade y para la sociedade: tal es el fundamento de la educación social ${ }^{10}$. (VIGOTSKI, 1997, p.125)

O teor de sua acepção reside na educação escolar de alunos com deficiência intimamente ligada à vida associada, perspectivada, colaborativa, cooperativa, produtiva. Ou melhor, trata-se de vincular a vida escolar aos processos sociais mais amplos. A escola se configura como lugar por excelência de organizar as crianças (com deficiência) na vida circundante.

O qualificativo social da educação, que pode soar hoje em dia como redundante, nas discussões de Vigotski sobre a educação especial, ganha um estatuto significativo. Trata-se de um constructo que estava em pauta naquele contexto histórico com vistas para a transformação social. E é por meio dele que o autor contesta a abordagem quantitativa das limitações orgânicas e inverte o foco de uma educação assistencial e tecnicista para uma educação orientada para o desenvolvimento humano.

Probablemente la humanidade vencerá, tarde o temprano, a la cegueira, a la sordera y a la debilidad mental. Pero las vencerá mucho antes en el plano social y pedagógico que en el plano médico y biológico. (...). La educación social vencerá a la defectividad $^{11}$. (VIGOTSKI, 1997, p.82)

Essa ideia está alicerçada a premissa de que o homem ao dominar os processos que determinam a própria natureza, produz efeitos na sua própria constituição biológica, torna-se artificie de si mesmo (PINO, 2000; SHUARE, 2017). "A transformação biológica do homem não representa um pré-requisito senão que, ao invés disso, é resultado da libertação social do homem" (VIGOTSKI, 2004, s/p). Liberdade aqui entendida não no sentido liberal/naturalista da ideologia dominante - os homens são livres para prosperar, sendo o fracasso ou sucesso atribuídos aos defeitos ou méritos individuais -; mas no sentido de uma conquista compartilhada, aliada a uma vontade coletiva, que nucleia possibilidades de transformação ou manutenção de determinado processo social; o que demanda "ampliação das capacidades simbólicas e culturais de cada pessoa num contexto societário livre da expropriação de uma classe por outra" (DELARI JUNIOR, 2013, p.52).

Assim, ao postular que a compensação social do déficit somente pode ser produzida na presença de uma vida social livre, Vigotski (1997) nos convoca a projetar processos educacionais que elevem a atividade coletiva e as formas de colaboração; que tomem a heterogeneidade como fonte vivificante do desenvolvimento humano; que se embasem no curso dialético da educação comum e especial, ou seja, que crie a síntese entre as leis gerais de desenvolvimento e suas manifestações específicas, o genérico e o idiossincrásico, o coletivo e o singular.

\section{Considerações Finais}

Em se assumindo que os contrários em luta e em movimento tendem a nova unidade de nível superior (CURY, 1989), consideramos as relações contraditória das determinações sociais que perpassam a educação inclusiva e salientamos, com isso, o potencial criativo e transformador da educação e do desenvolvimento de crianças com deficiência.

Apontamos, por meio da concepção de educação social de Vigotski (1997, 2004), um projeto educacional que se organize no sentido de criar mediadores/sistemas culturais auxiliares que alterem qualitativamente o funcionamento psíquico; que, por meio da atividade laboral, torne acessíveis aos sujeitos com deficiência as formas conscientes de desenvolvimento da atividade coletivamente organizada; que considere os modos singulares de apropriação das formas de conduta socialmente elaboradas; que potencialize processos de mediação pedagógica e sustente a participação efetiva de cada pessoa nas múltiplas dimensões da vida coletiva.

Nesta perspectiva, a educação associada à atividade laboral com foco para a formação integral e desenvolvimento cultural da personalidade corrobora com uma práxis político-pedagógica que se organize com base na relação dialética entre o que a humanidade produziu por meio do trabalho e o que os indivíduos (com deficiência) podem vir a ser: partícipes da transformação social. 


\section{Notas}

1 Notas de minicursos proferidos por Inna Koperanova e Tatiana Akhutina, realizados nos dias 30 e 31 de agosto de 2011 no Centro Universitário de Brasília - Faculdade de Ciências da Educação e da Saúde, durante a Semana de Psicologia.

2 A grafia do nome do autor varia em diferentes traduções. Optamos por uma só forma no texto, porém preservando as indicações diferenciadas nas referências bibliográficas.

3 É a sociedade e não a natureza que deve figurar em primeiro lugar como fator determinante da conduta do homem. (tradução nossa)

4 Que resultados podem existir quando o aluno é apenas um executor, para quem outro realiza o trabalho da organização e que, por não estar habituado a colaborar nas tarefas, torna-se um inválido quando sai da escola? (tradução nossa)

5 Ainda que as crianças com deficiência intelectual levem mais tempo para aprender, (...), ainda que, finalmente, sejam ensinadas de outra maneira, por meio de métodos e procedimentos especiais, adaptados às características específicas de sua condição, devem aprender o mesmo que todas as crianças, receber a mesma preparação para a vida futura, para que mais tarde possam participar, em certa medida, em conjunto com os demais. (tradução nossa)

6 Órgãos sociais. (tradução nossa)

7 Assim como o curso de uma torrente é delimitado pelas margens e pelo canal, a linha psíquica orientadora, o objetivo da vida do homem em desenvolvimento e crescimento, é delimitado pela necessidade objetiva do canal social e das margens sociais da personalidade. (tradução nossa)

8 Vias colaterais de desenvolvimento cultural. (tradução nossa)

9 Não devemos duvidar que é preciso educar não um cego, e sim uma criança. (tradução nossa)

10 A ideia central consiste em que a educação se considera como parte da vida social e como participação organizada das crianças nessa vida. A educação e o ensino na sociedade, através da sociedade e para a sociedade: tal é o fundamento da educação social. (tradução nossa)

11 Provavelmente a humanidade vencerá, tarde ou cedo, a cegueira, a surdez, a deficiência intelectual. Mas as vencerá muito antes no plano social e pedagógico que no plano médico e biológico. (...). A educação social vencerá a deficiência. (tradução nossa)

\section{Referências}

BARROCO, S.M.S. A educação especial do novo homem soviético e a psicologia de L.S. Vigotski: implicações e contribuições para a psicologia e a educação atuais. $414 \mathrm{f}$. Tese (Doutorado em Educação) - Faculdade de Ciências e Letras da Universidade Estadual Paulista Júlio de Mesquita Filho, Araraquara, São Paulo, 2007.

CARVALHO, M. F. O aluno com deficiência intelectual na escola: ensino, aprendizagem e desenvolvimento humano. In: MELETTI, S.M.F.; KASSAR, M.C.M. Escolarização de alunos com deficiências: desafios e possibilidades. Campinas: Mercado de Letras, 2013, p. 203-242.

CARVALHO, S. R. de; MARTINS, L. M. A sociedade capitalista e a inclusão/exclusão. In: FACCI, M. G. D.; MEIRA, M. E. M.; TULESKI, S. C. A Exclusão dos "Incluídos": uma crítica da psicologia da educação à patologização e medicalização dos processos educativos. 2. ${ }^{\mathrm{a}} \mathrm{ed}$. Maringá: Eduem, 2012, p. 19-32.

CURY, C.R.J. Educação e contradição: elementos metodológicos para uma teoria crítica do fenômeno

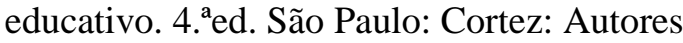
Associados, 1989.

DAINEZ, D. A formação da criança com deficiência intelectual nas condições da educação inclusiva: algumas considerações. In.: MONTEIRO, M.I.B; FREITAS, A. P.; CAMARGO, E.A.A.. Relações de ensino na perspectiva inclusiva: alunos e professores no contexto escolar. Araraquara, SP: Junqueira\&Marin, 2014.

DAINEZ, D. Desenvolvimento e deficiência na perspectiva histórico-cultural: contribuições para educação especial e inclusiva. Revista de Psicología. Sección Temática: Psicología HistóricoCultural, v.26, n.2, p. 1-10, 2017.

DELARI JUNIOR, A. Princípios éticos em Vigotski: perspectivas para a psicologia e a educação. Nuances: estudos sobre Educação, Presidente Prudente, SP, v.24, n.1, p.45-63, 2013.

DEMO, P. Metodologia do conhecimento científico. ed.1. São Paulo: Atlas, 2000.

ENGELS, F. Sobre o papel do trabalho na 
transformação do macaco em homem. Rocket Edition, 1999.

FREITAS, A. P. de, MONTEIRO, M. I. B.; CAMARGO, E. A. A. Contradições no/do cotidiano escolar: professores e alunos com deficiência diante do ensino na diversidade. Horizontes, Campinas, SP, v. 33, n. 2, p. 27-36, 2015. Disponível em https://revistahorizontes.usf.edu.br/horizontes/articl e/view/245. Acesso 01 mai. 2018.

FREITAS, A. P. de; DAINEZ, D. Estágio extracurricular e educação inclusiva: dilemas e percepções de alunas do primeiro ano de um curso de pedagogia. Revista Interinstitucional Artes de Educar, Rio de Janeiro, v.4, p.79-100, 2018.

FREITAS, L. C. Avaliação: para além da "forma escola". Educação: Teoria e Prática - v. 20, n.35, p. 89-99, 2010. Disponível em http://www.periodicos.rc.biblioteca.unesp.br/index. php/educacao/article/view/4086/3294. Acesso 05 jun. 2018.

GARCIA, R. M. C. Educação especial na perspectiva inclusiva: determinantes econômicos e políticos. Comunicações, Piracicaba, SP, v.1, p.726, 2016.

JANNUZZI, G. M. A luta pela educação do deficiente mental no Brasil. Inserir edição. São Paulo, SP: Cortez: Autores Associados, 1985.

JANNUZZI, G. M. A educação do deficiente no Brasil: dos primórdios ao início do século XXI. 2. ed. Campinas: Autores Associados, 2006.

KASSAR, M.C.M. Percursos da constituição de uma política brasileira de educação especial inclusiva. Revista Brasileira de Educação Especial, v.17, p.41-58, 2011. Disponível em: http://www.scielo.br/pdf/rbee/v17nspe1/05.pdf. Acesso em: 01 nov. 2015.

KUHNEN, R. T. A concepção de deficiência na política de educação especial brasileira (19732016). Revista Brasileira de Educação Especial, v.23, n.3, p.329-334, 2017.

LEONTIEV, L.A. O desenvolvimento do psiquismo. ed. 1. Lisboa: Livros Horizontes, 1978.

LURIA, A.R. Curso de Psicologia Geral:
Introdução Evolucionista à Psicologia. ed.1. Rio de Janeiro: Civilização brasileira, 1979.

MARX, K. O Capital: crítica da economia política. Livro 1. Tradução Rubens Enderle. E-book. São Paulo: Boitempo Editorial, 2011. Disponível em https://www.boitempoeditorial.com.br/produto/ocapital-livro-i-653. Acesso 01 mai. 2018.

MARX, K.; ENGELS, F. A Ideologia Alemã. São Paulo: Boitempo Editorial. Tradução Rubens Enderle, Nélio Schneider, Luciano Cavini Martorano, 2007.

MARX, K.; ENGELS, F. Textos sobre Educação e Ensino. Edição Eletrônica (e-book). Campinas, SP: Navegando, 2011. Disponível em https://www.marxists.org/portugues/marx/ano/mes/e nsino.pdf. Acesso 01 mai. 2018.

PADILHA, A. M. L.; OLIVEIRA, I. M. Inclusão escolar, diversidade e desigualdades sociais. In: PADILHA, A. M. L.; OLIVEIRA, I. M.. Educação para todos: as muitas faces da inclusão escolar. Campinas: Papirus, 2013, p. 17-58.

PLETSCH, M.D. Repensando a inclusão escolar: diretrizes políticas, práticas curriculares e deficiência intelectual. ed.1. Rio de Janeiro: Nau: Edur, 2010.

PINO, A. O social e o cultural na obra de Vigotski. Educação \& Sociedade, Campinas, SP, ano 21, n.71, p.45-78, 2000.

TULESKI, S. C. Vygotski: a construção de uma psicologia marxista. 2. ${ }^{\text {a }}$ ed. Maringá: Eduem, 2008.

SHUARE, M. A psicologia soviética: meu olhar. ed.1. São Paulo: Terracota, 2017.

SIEMS-MARCONDES, M.E. R.; CAIADO, K. R.M. Educação especial: da filantropia ao direito à escola. In: CAIADO, K.R. M. (org.). Trajetórias escolares de alunos com deficiência. São Carlos, SP: EdUFSCar, 2013.

STETSENKO, A. Vygotsky's theory of method and philosophy of practice: implications for trans/formative methodology. Educação, Porto Alegre, v. 39, p.32-41, 2016. . The transformetive mind: explanding 
Vygotsky's approach to development and education. New York: Cambridge University Press, 2017.

VIGOTSKI, L. S. Psicologia concreta do homem. Educação \& Sociedade, ano 21, n. 71, 2000, p. 2344.

VIGOTSKI, L.S. A transformação socialista do homem (1930). Trad. de Nilson Dória. Marxists
Internt Archive, 2004. Disponível em: https://www.marxists.org/portugues/vygotsky/1930/ mes/transformacao.htm. Acesso em 13 jun.2018.

VYGOTSKI, L. S. Obras Escogidas, v. III. Madrid: Visor Distribuiciones, S.A., 1995.

VYGOTSKI, L.S. Obras Escogidas, v.V. Madrid: Visor Distribuiciones, S.A., 1997.

\section{Sobre as autoras}

Débora Dainez é Doutora em Educação e Pós-Doutora em Psicologia Educacional pela Unicamp, PósDoutoranda no Programa de Pós-Graduação em Saúde, Interdisciplinaridade e Reabilitação da Unicamp.

Ana Paula de Freitas é Doutora em Educação pela Unicamp, Docente do Programa de Pós-Graduação Stricto Sensu em Educação da Universidade São Francisco - Campus Itatiba/SP.

Recebido em julho de 2018.

Aprovado em outubro de 2018. 